\title{
Do Stock Market Fluctuations Affect Suicide Rates?
}

\author{
Tomasz Piotr Wisniewski ${ }^{1}$ \\ The Open University \\ Faculty of Business and Law \\ Department of Accounting and Finance \\ Walton Hall \\ Milton Keynes, MK7 6AA, UK \\ Phone: +44 1908655020 \\ E-mail: tomasz.wisniewski@open.ac.uk
}

\author{
Brendan John Lambe \\ De Montfort University \\ Leicester School of Business \\ The Gateway \\ Leicester, LE1 9BH, UK \\ Tel: +44 1162013833 \\ E-mail: brendan.lambe@dmu.ac.uk
}

${ }^{1}$ Corresponding author. 


\title{
Do Stock Market Fluctuations Affect Suicide Rates?
}

\begin{abstract}
This paper uncovers a new influential factor driving suicidal behavior. Using an international sample, we document a robust and significant inverse relationship between stock market returns and the percentage increase in suicide rates. Trends in suicides are affected by market fluctuations both contemporaneously and at a lag. This predictive quality of stock returns offers the potential to implement proactive suicide prevention strategies for those who could be affected by the vagaries of the market and general economic downturns.
\end{abstract}

Keywords: Suicides; Stock Market; Stock Returns

JEL Codes: G11; 112; 118 


\section{Introduction}

The Bankers' Panic of 1907 sent shockwaves through the market causing US stock prices to halve in value from its previous year's high point. This was reflected in mortality statistics for 1908, which showed that the percentage of deaths attributed to suicide amongst bankers, brokers and officials of companies was over twice as high as that of the general population (Department of Commerce and Labor, 1909). Suicides on Wall Street have become mythologized through the popular press and cinema (Stacks and Bowman, 2014). Finance folklore alludes to traders jumping out of windows following the 1929 crash (Rogers, 1929), although some commentators questioned the accuracy of these accounts (Lowenthal, 1987; Galbraith, 1997: 128). Despite the controversy, there has been no rigorous investigation as to whether stock market collapses compel people to take their own lives. In a society where success is measured in material terms, one would suppose that a substantial loss in wealth could lead to such a desperate act. However, this supposition remains untested in the academic literature and our study attempts to address this gap.

Suicide represents and creates intense suffering and results in a tragic loss in terms of human capital. It is estimated that 788,000 deaths were attributable to suicide in 2015 , translating into one death every 40 seconds (World Health Organization, 2018). The WHO has identified suicide as a public health priority and has tasked its member states with achieving a $10 \%$ reduction in their respective rates by 2020. In order to be successful, prevention strategies have to address the underlying causes and motivations behind the act itself. The purpose of our inquiry is to contribute to the understanding of what may induce an individual to kill themselves. If stock market fluctuations drive these desperate decisions, policies pertaining to mental health will need to take market movements and the consequent financial strain into account.

Prior literature indicates that there could be a link between financial distress and the health status of individuals. The findings of Currie and Tekin (2015) tell us that foreclosures are traumatic events which can induce heart attacks, strokes and psychiatric difficulties, as is evidenced by an increased number 
of hospital visits. Lin et al. (2013) support this notion by documenting that a fall in house prices can be linked to increased use of medications to treat depression. As economic strain is becoming more recognized as a factor that negatively impacts upon mental wellbeing, it is important to realize the hazards that stock price fluctuations present. Exposure stretches beyond those who are directly invested in equities, as large swathes of the general populace are dependent on pension funds for their retirement income. Furthermore, stock prices can mirror the general economic circumstances and the financial standing of employers. As adverse movements in equity values can be considered a stressor, the question arises as to whether this may propel individuals to commit suicide.

It is important to note that the stock market index is usually considered a leading indicator capable of predicting future macroeconomic trends (Stock and Watson, 1989; Estrella and Mishkin, 1998). Thus, if individuals are forward-looking, stock returns may be a better predictor of suicide rates than the aggregate economic indices, which offer only a retrospective view of the situation. If sudden changes in stock prices signal future financial hardship, careful monitoring of market conditions could aid policy makers in designing and implementing pro-active strategies to manage potential suicide epidemics.

In what follows, we utilize a panel data set of 36 countries to verify whether the current and lagged stock index returns affect changes in suicide rates. In doing so, we consider data aggregated within a given country, as well as statistics separated by gender. A wide range of control variables have also been included to capture the business cycle and the corresponding socioeconomic conditions. We find that contemporaneous returns and their previous values drive the changes in suicide rates for the general population. This finding persists when the data is broken down by gender. Among the macroeconomic control variables, changes in unemployment and inflation appear to exert the strongest influence. Increases in female labor market participation and prior health expenditure appear to stave off growth in male suicide rates. Women decrease their proclivity to commit suicide whenever they display a greater tendency to bear children and when the alcohol consumption in the general population falls. 
The remainder of the paper is organized as follows. The next section reviews the literature on how the human condition is affected by material wealth and considers the existing theoretical views on suicide. Section III discusses known determinants of suicide rates that we include in our empirical model. Following on from that, in Section IV, we present a list of data sources, summary statistics, as well as bivariate correlation analysis. The penultimate section analyses the results from the multivariate models employed in the study. We end the paper with conclusions and recommendations for financial advisers and policy-makers in the areas of finance and public health.

\section{Literature review}

A long-standing scientific question is whether material riches can affect the level of individual happiness and mental health. Higher income results in greater purchasing power that allows one to fulfill many desires and affords more personal freedoms. Indeed, the academic literature focusing on individual-level data has reported modest positive correlations between income and subjective wellbeing (see for instance Mullins, 1992; Frey and Stutzer, 2000; Blanchflower and Oswald, 2004a, 2004b). The relationship between income and happiness, however, appears to be nonlinear, in that the satisfaction derived from additional cash inflow is lower at higher income levels (Frey and Stutzer, 2000). Furthermore, as people tend to compare themselves with others, it may be their relative rather than absolute income that determines how satisfied they are with their lives (Luttmer, 2005).

When examining these questions, the direction of causality may not always be clear. Does money buy happiness, or are happy and healthy people more productive? The reverse causality problem is mitigated in situations, where large exogenous income shocks transpire. Using this logic, Lindahl (2005) examined a sample of Swedish lottery winners and showed that sudden income augmentation leads to improved health status and lower mortality. Gardner and Oswald (2007) and Apouey and Clark (2015) observed the salubrious effects of lottery prizes on the mental wellbeing of British people. However, the general health level was not improved, as winners started to engage in more social drinking and smoking (Apouey and Clark, 2015). Another paper focusing on windfalls by Kim and Ruhm 
(2012) found that bequests created no substantial health effects, despite the fact that the recipients increased their expenditure on healthcare.

Another strand of research has been conducted using aggregated data on subjective well-being. Robust evidence has been found in a cross-section of countries showing that individuals living in wealthier nations tend to be happier on average (Inglehart and Klingemann, 2000; Diener and BiswasDiener, 2002). Time series investigations, however, conclude that despite a sharp real GDP per capita increase over time, the average happiness level has remained largely unaltered (Easterlin, 1995; Blanchflower and Oswald, 2004b). One rationalization for this phenomenon is related to the fact that people undergo a process of adaptation and have continuously growing aspirations (Frey and Stutzer, 2002).

Happiness aside, a strand of health economics literature suggests that mortality and morbidity are related to the business cycle. Ruhm $(2000,2005)$ argues that the general state of physical health within the population improves during recessions, when the opportunity cost of time is lower. This allows individuals to engage more with health-promoting activities, such as exercise and other preventative behaviors. Financial constraints inhibit indulgent and self-destructive tendencies like overeating, as well as excessive alcohol and tobacco use. In recessionary periods, the pressures placed on an individuals' health owing to working longer hours are alleviated, resulting in a lower level of exertion. One important exception to this countercyclicality of health that Ruhm (2000) identifies relates to suicide, which is the only proxy for mental health used in his study.

Mental health has been shown to be undermined through financial adversity. Ganzini, McFarland and Cutler (1990) show that adults who suffered a catastrophic financial loss are more susceptible to developing major bouts of depression. Recent data from the credit crunch period revealed that both a decline in housing wealth and difficulties with mortgage repayments are a significant contributor to psychological distress (Gili et al, 2012; Yilmazer et al., 2015). Evidence on the role that financial stressors play in the development of mental illness was also obtained in a natural disaster context. 
Galea et al. (2008) show that individuals who suffered financial losses caused by Hurricane Katrina were more likely to suffer from posttraumatic stress disorder.

One of the most regrettable and irreversible decisions undertaken by those mentally affected by a large monetary loss is that of the taking of their own life. Hamermesh and Soss (1974) present an economic theory which propounds that individuals commit suicide when their discounted lifetime future utility falls below an acceptable threshold. The future utility is a function of several variables, amongst which permanent income level features prominently. In situations of financial catastrophe, the benefit a person may derive from their life circumstances can diminish beyond the point that they can endure. An earlier theory of suicide published by Durkheim (1897) embraces sociological paradigms and refers to the concept of anomie; a state of being where there is a disjuncture between a person's life expectations and the reality of their existence. The level of anxiety resulting from a lack of social integration reaches a point where it creates within the individual an urge to take their own life. Important in this explanation is the departure from seeing suicide as a consequence of insanity and rather viewing it as a side effect of socio-economic disquiet. Anomie, argues Durkheim, is a condition which reflects the failure of value-based norms and standards, leading to sense of purposelessness and a lack of integration. In the empirical model that follows, we employ a wide range of controls that capture the social conditions within which suicides occur. A more focused link between economic circumstances and destructive human behavior is offered by Henry and Short (1954) who propose their frustration aggression theory. This postulates the idea that a negative impact on individual personal economic circumstances may induce a person to engage in acts of aggression that are often self-targeted. An improvement in economic conditions therefore lessens the degree of frustration felt by individuals and thus the tendency to do themselves harm. This allows the authors to coherently argue for a link between suicide rates and business cycles.

The nexus between macroeconomic fluctuations and suicide has been investigated by a number of scholars (for a literature review see Oyesanya et al. (2015)). However, an explicit attempt to model 
the prevalence of voluntary deaths as a function of stock market returns has not been made to date. Where work has been completed, it is in the tracing of the relationship between mental health and the vagaries of the market. For instance, Mclnerney et al. (2013) link the 2008 stock market collapse with the diagnosis as well as treatment of depression. Engelberg and Parsons (2016) examine hospital admissions for psychological conditions in California and find that they are inversely related to stock returns. In a similar vein, Cotti et al. (2015) show that negative returns trigger risky health behavior, such as excessive use of tobacco and alcohol. What is surprising, is that the literature neglects to consider suicide in this context, even though wealth decreases caused by market gyrations clearly have the potential to affect the mental state of investors.

\section{Determinants of Suicide Rates}

A broad range of socio-economic factors has been proposed in the literature to account for suicide rates. Variables related to business cycles, labor market status, family structure, demographics and risky health behaviors have been considered in prior studies. In this section, we review scientific findings pertaining to these indicators.

Beginning with macroeconomic variables, we first consider income. In the theoretical model of Hamermesh and Soss (1974), high levels of permanent income enhance lifetime utility, discouraging suicidal acts. Conversely, a reading of Durkheim (1897) would suggest that failure on the part of society to integrate and regulate individuals is more likely in the presence of economic extremes. This implies a polarised relationship between income and suicide rates, with maximums being reached in the context of sharp expansions and contractions (Lester, 2001). Many empirical studies examining the link between income or real GDP growth and suicide rates have found negative covariations, this lends credence to the Hamermesh and Soss (1974) model (Kimenyi and Shughart, 1986; Brainerd, 2001; Mathur and Freeman, 2002; Helliwell, 2007; Chen et al., 2009). It is important to note, however, that a number of researchers report the opposite result (Simpson and Conklin, 1989; Lester, 1995; 
Freeman, 1998; Jungeilges and Kirchgässner, 2002). Consequently, it has to be concluded that both the theoretical and empirical literatures present divergent views on the effect of income.

Evidence with respect to unemployment is more clear-cut, with the vast majority of studies reporting a positive association with suicide mortality (Huang, 1996; Lewis and Sloggett, 1998; Freeman, 1998; Klick and Markowitz, 2006; Bar et al., 2012; Phillips and Nugent, 2014). First, unemployment reduces permanent income and therefore can undermine satisfaction with life. Second, people with mental health problems can be stigmatized in the labor market and experience prolonged spells of unemployment (for a full review see Stuart, 2006). The strain of joblessness can also contribute to the manifestation and progression of mental illness (Paul and Moser, 2009). Third, an unemployed person may lose their sense of life's purpose and their feeling of integration within society echoing the anomic condition described by Durkheim (1897).

An untenable cost of living may be another factor driving suicide rates. An early discussion of this notion can be found in Morselli (1882, p. 152) with reference to the price of food staples. In an economy where wages are sticky and labor contracts are renegotiated on a periodic basis, inflation in consumer price index lowers the real income and purchasing power of individuals in the short term. The emotional distress that follows as a result, particularly among the less affluent, may lead to responses that are extreme in nature. The empirical evidence regarding the link between inflation and suicide rates can be best described as mixed. Huppes (1976) finds a strong positive association between the two for the Netherlands and the US, while Gavrilova et al. (2000) note that the 1992 Russian market reforms, which relaxed prices controls, led to an escalating inflation rate and an increase in self-induced violent deaths. On the other hand, using an international sample, Matsubayashi and Ueda (2011) fail to find a similar statistically significant relationship. It is also worth mentioning that economists sometimes aggregate the level of unemployment and inflation into one indicator which is referred to as the misery index. When considering US data, Yang and Lester (1999) argue that the correlation between suicide rates and the misery index is exceptionally high. 
In addition to the macroeconomic indicators, our study controls for recognized social risk factors which contribute to suicidal behavior. Durkheim (1897) espoused the idea that a high degree of social integration, which can be to some extent captured by family ties, reduces the instance of suicide. One variable taken to proxy for familial cohesion is the fertility rate. Using an international sample, Rodríguez Andrés (2005) confirmed that birth rates are negatively associated with both male and female suicides. However, we must introduce a number of caveats to this picture. Caring for children can exert its own financial and emotional strain on the individual, which in certain circumstances can overpower this beneficial relationship. For instance, Mäkinen (1997) shows that illegitimate births and teenage pregnancies are positively correlated with suicidal behavior across both genders. Further consideration is that when the responsibility of childrearing is passed to older generations, this can intensify the pressure on grandparents, leading to increased suicidal tendencies amongst older men (Chen et al., 2009).

Another measure of familial cohesiveness is the strength of formalized partnerships, the breakdown of which has been shown empirically to precipitate suicidal behavior (see for instance Burr et al., 1994; Minoiu and Rodríguez Andrés, 2008; Mäkinen, 1997). Generally speaking, researchers agree that the emotional and financial upheaval attached to a marriage dissolution can induce self-destructive behavior. The effect, however, may not be uniform across gender. A number of studies show that, compared to females, males are more likely to commit suicide as a result of experiencing divorce (Chen et al., 2009; Neumayer, 2003; Koo and Cox, 2008; Matsubayashi and Ueda, 2011). Potential explanations for this difference are discussed in Chen et al. (2012) and relate to the fact that courts tend to favor women in decisions over custody and financial support. In addition, divorce may have a more liberalizing effect upon women, particularly those who are already enjoying a certain level of financial independence. Finally, in abusive relationships, an option to divorce unilaterally can empower the victim and has been shown to reduce the female suicide rate (Stevenson and Wolfers, 2006). 
The engagement of the female demographic as part of the labor force should be also considered a factor relevant to modeling self-inflicted fatalities. Potential role conflicts and erosion of traditional preconceptions of the family structure can heighten the risk of a negative response from those adversely affected. Several studies linked high female labor force participation to increased prevalence of suicides (Mäkinen, 1997; Stack, 1998; Neumayer, 2003). However, the supplementation of family income by women can relax financial household pressures and offer them opportunities to integrate into society. The ultimate net effect of female labor force participation will depend upon the relative importance of the abovementioned drawbacks and benefits. For instance, Burr et al. (1994) document a reduction in suicides as a result of more women being at work. Similar results are reported for urbanized areas in Faupel et al. (1987). Consequently, it is clear that the findings with regard to female labor activity can be sample-specific and will depend upon the cultural and economic context.

A further determinant of suicide is the rate of alcohol consumption within the general populace. Acutely intoxicated individuals exhibit overly emotive and impulsive behavior, poor decision-making and relaxed inhibitions. Taken individually or together these behaviors could enhance suicidal urges. Additionally, chronic alcohol abuse is often embedded in the pathology of mental illness and leads to social isolation. A Canadian study conducted by Smart and Mann (1990) revealed that suicide is linked to major proxies for alcohol problem indicators, such as dependency levels and liver cirrhosis. Similar findings were obtained in a sample of Scandinavian countries by Norström (1988) and the US (Stack and Wasserman, 1993). Landberg (2009) examined the impact of aggregate per capita alcohol consumption on suicide related deaths broken down by gender. Although there was no statistically significant relationship for the male sub-sample, females exhibited greater sensitivity. An increase in per capita consumption of spirits by one liter raised the female suicide rate by $16 \%$. It is conceivable that this may be as a result of the distress caused by a heavy drinking partner and the domestic violence that could ensue as a result (Leonard, 2009). 
Other societal characteristics may play a part in the manifestation of psychiatric morbidity. For example, population density has been noted in some studies to be a contributory factor to suicidal behavior. Population concentrations can affect the degree of social cohesiveness and access to mental health services. A sense of isolation may occur in highly urbanized environments, just as much as it can in remote locations. On one hand, large geographical distances between individuals can undermine the process of social integration and potentially lead to higher suicide rates (Minoiu and Rodríguez Andrés, 2008). On the other hand, in rural areas with low population densities people tend to live in settlements, which increases proximity to others and may create a tightly knit community support structure (Levin and Leyland, 2005; Stark et al., 2007). Similar considerations are also apposite to highly populated regions. Emotional distance and a sense of alienation can arise even when people live cheek by jowl (Burr et al., 1994). Taking into account the ambiguities involved, it may be difficult make to a priori predictions about the direction of the relationship between suicide rates and population density.

The question that arises at this stage is to what extent can spending on healthcare provision counter suicidality. No clear consensus has emerged from the studies that have investigated this issue. In their US-based sample, Minoiu and Rodríguez Andrés (2008) found that increased public health expenditure was associated with a lessening of suicide risk for the following year. Their results imply that the effects of treatment may not be felt immediately and are primarily observed for men. Desai et al. (2005) support this position by tracing a link between the level and quality of mental health care and suicide mortality, whilst Matsubayashi and Ueda (2011) point to efficacious aspects of national suicide prevention programs. Shah and Bhat (2008) detract somewhat from this argument by showing that rates of voluntary deaths amongst the elderly are not affected by mental health policy and funding.

\section{Data}


The main variable of interest in this study is the suicide rate, which is sourced from the OECD Health Statistics database. This rate is expressed per 100,000 people and the data is available for 41 countries. For 36 of these, the $\mathrm{MSCl}$ value-weighted country stock market indices are available from Thomson Reuters Datastream. Based on these indices, we compute dollar-denominated continuously compounded returns to be subsequently used in our analysis. These two key variables define the dimensions of our primary unbalanced panel, which for some of the nations starts as early as 1970 and ends in 2014. The exact list of countries included in our sample can be found in the appendix to this paper. We collect data on all of the control variables, which were described in detail in the previous section. Table I lists these variables alongside their exact definitions and data sources.

[Insert Table I about here]

[Insert Table II about here]

Table II provides basic summary statistics and displays results of panel unit root tests proposed by Im, Pesaran and Shin (2003) and Maddala and Wu (1999). The problem of potential nonstationarity is of great importance, as the presence of unit roots can render our regression results spurious. It is evident that suicide rates have a stochastic trend component and that they need to be transformed in order to eliminate this problem. Pierce (1967) noted that residuals from suicide rate models exhibit an exceptionally high degree of autocorrelation, which leads to estimation difficulties. This was a perceptive comment as it was made before the concept of non-stationarity was introduced into the body of econometric literature by Dickey and Fuller (1979). Guided by these considerations, we decide not to focus on the data in levels and instead compute percentage change in the suicide rate. This indicator acts as a dependent variable in the econometric specifications that follow. Other explanatory variables have also been expressed as a percentage rate of change in order to remove unit roots and make our analysis logically consistent. We note in passing that GDP growth and inflation do not need to be transformed, as they are already expressed as a rate of change. 
The averages reported in Table II shed more light on the socio-economic trends transpiring across societies. Firstly, the incidence of suicide within the general population is around 15 per 100,000 people annually and this rate has increased over time. Although men are 3.2 times more likely to complete a suicidal act than women, this statistic has to be interpreted with caution as Mościcki (1994) notes that the majority of suicide attempters are female. The observed average stock market return of $6.3 \%$ materialized in an environment characterized by growing GDP and consumer prices. Increasing female labor force participation coincided with declines in fertility and more frequent marriage dissolutions. Somewhat worryingly, both the unemployment rate and alcohol consumption trended upward during our sample period. Finally, the population density increased and the cost of supporting healthcare relative to GDP has escalated over time.

[Insert Table III about here]

Table III reports estimates of correlation coefficients between the percentage changes in the suicide rates and our explanatory variables. We also consider Returns and pcHealth variables at a lag, as the impact of healthcare spending on suicides may not be immediate (Minoiu and Rodríguez Andrés, 2008) and because stock market returns tend to reflect anticipated future economic circumstances (Stock and Watson, 1989; Estrella and Mishkin, 1998). Most strikingly, Table III highlights a strong negative association between stock market fluctuations and changes in the incidence of voluntary death. The caveat to interpreting this preliminary finding is that a simple correlation analysis does not control for other important factors that are likely to affect suicide rates. The estimates also lend support to the theory propounded by Hamermesh and Soss (1974), as some of our evidence demonstrates that suicide rates decline in times of rising income and falling unemployment. The variables labelled pcFertility and pcDivorces, which proxy for family cohesiveness, or lack thereof, appear to significantly affect suicidality within the population. Additionally, the correlation analysis suggests that a rising population density contributes to suicidal tendencies for both genders. 


\section{Empirical Results}

Since our data has an unbalanced panel structure, we utilize panel data methods in our modelling. The simplest estimation approach available in this particular setting is pooled OLS, which assumes that unique attributes of countries are not present and that the regression parameters are identical for all cross-sectional units. One could explicitly incorporate the heterogeneity between different nations by considering either a random or fixed effects panel model. In the context of our modelling, however, the Hausman (1978) test indicated that residuals from a random effect model are correlated with the regressors in many of the specifications, implying that this method will not produce consistent estimators of the true population parameters. Consequently, we resort to using fixed effects panel techniques, which deliver in terms of consistency and allow the regression intercept to vary over crosssectional units.

Several considerations emerge when selecting the appropriate estimation method for the fixed effects panels. First, it may be argued that the quality of suicide data may not be uniform across nations. In societies where suicides are stigmatized for cultural or religious reasons, suasion may be exerted on the Coroner to misreport the cause of death, a phenomenon first reported by Morselli (1882). These country-specific measurement errors could become reflected in residuals and lead to cross-sectional heteroscedasticity. To counter this problem, we estimate our fixed effects panel specifications using a feasible generalized least squares approach. This method permits us to assign lower cross-sectional weights to countries with high residual variances, which may to some extent reflect the inaccuracies inherent in the data. The second potential hindrance is the serial correlation of residuals, which can lead to an incorrect estimation of parameter standard errors and test statistics. To address this issue, we use the Arellano (1987) estimation technique, which leads to correct inferences even in instances when errors for a cross-section are heteroscedastic and autocorrelated.

[Insert Table IV about here] 
[Insert Table $V$ about here]

[Insert Table VI about here]

Table IV presents regressions linking the percentage change in total suicide rates to a range of explanatory variables, while Tables $\mathrm{V}$ and $\mathrm{VI}$ show analogous estimations broken down by gender. The first two models reported in the table differ in their econometric approach, but essentially represent the simplest specification where all controls are omitted. In contrast, the fixed effects model displayed in column (3) includes a full set of independent variables, many of which prove to be statistically insignificant. Our parsimonious and preferred specification reported in the last column excludes all insignificant factors. The exclusion procedure was iterative in that we started with specification (3), dropped the control variable with the highest $p$-value and re-estimated the model. Subsequent controls were removed one-by-one in a similar manner until all of the remaining explanatory factors exhibited statistical significance.

In line with our expectations, there is an inverse relationship between stock market fluctuations and suicidal tendencies within society. This relationship is quite robust for both genders, as is evidenced by the statistical significance of Returns across the different model specifications. Interestingly, lagged stock market movements can also be considered an influential determinant. Two rationalizations can be put forward to explain this delayed reaction. First, one may argue that the ultimate decision to take one's life can happen after a prolonged period of emotional anguish instigated by material loss. Second, returns may be predictive of future economic circumstances and hardship. Since stock market investors are forward-looking, expectations about the future will drive present returns. In our sample, we find that current returns appear to reliably predict next year's GDP growth (correlation coefficient $=0.4497, p$-value $=0.0000$ ). This leading indicator characteristic of stock price fluctuation could underpin the observed dynamic relationship with suicide. Importantly, returns remain significant, even after controlling for economic conditions. They not only seem to reflect the underlying macroeconomic fundamentals, but also appear to act as a useful barometer of 
public sentiment (Baker and Wurgler, 2007). This sentiment evidently finds its reflection in the suicide statistics.

While the statistical significance of returns is difficult to refute, questions may be raised about the economic significance of our results. A useful illustration in this regard can be drawn from the 2008 stock market crash. To estimate the number of lives lost due to crash-related suicidal acts in our sample countries, we perform a simulation based on the parsimonious model for the change in the overall suicide rate (Table IV, Model 4). Additional data on population size from the World Development Indicators database had to be collected for the purposes of this exercise. According to our calculations, the 2008 stock market crash resulted in an additional 6,566 suicides across our 36 sample nations during the 2008-2009 period. ${ }^{2}$ To put this into context, this estimate is over twice as large as that of the total number of people killed in the 9/11 terrorist attacks (Riedman and Warden, 2017). Despite its importance, the problem described here has received little attention from the media and academic community.

Further insights about suicidal behavior can be gleaned from the regression estimates for the control variables. Since our interest is primarily in the statistically significant results, we focus on the parsimonious model specifications. For the overall sample, percentage changes in suicide rates are linked positively with rising unemployment. However, disaggregation according to gender reveals that men more easily succumb to suicidal urges in an economy that increasingly fails to fully utilize its workforce. Perhaps men feel the psychological impact more acutely as a result of the traditional cultural norms of gender roles within society. Inflationary pressures seem to exert a significant influence on the changing rate of suicide, regardless of whether we focus on men or women. Our findings in this respect contribute a note of clarity to the conflicting opinions extant in the literature (Huppes, 1976; Matsubayashi and Ueda, 2011).

\footnotetext{
${ }^{2}$ Please note that we need to consider a two-year assessment window due to the dynamic nature of the returnssuicide nexus.
} 
Macroeconomic considerations aside, the evolving nature of familial structures are of consequence to our dependent variable. In line with anomic theory, where a sense of purposelessness is part of the driving impetus behind suicides, women who decide to have children tend to extract a sense of purpose from this responsibility. A similar effect is not discernable among men, as the pcFertility variable is insignificant in the regressions reported in Table $\mathrm{V}$. The percentage change in female participation in the workforce has a significant bearing on trends in male suicide, as the burden of subsistence provision no longer rests solely with men. Increased representation of women in the workforce, however, appears to be inconsequential for determining their suicidality.

Our results with regards to health expenditure mirror those obtained by Minoiu and Rodríguez Andrés (2008). Healthcare spending is efficacious in reducing the incidence of suicide among men at a lag, but seems ineffective in altering the outcome for females. What would be beneficial for women is the implementation of successful alcohol prevention programs. This should incorporate elements of targeting the externalities of increased alcohol consumption amongst the populace. Our results indicate that females are adversely affected by higher alcohol use, possibly through being the victims of domestic violence (Leonard, 2009), which could lead them to take their own lives. The findings for men are insignificant and this is perhaps due to their use of alcohol as a coping mechanism (Pearlin and Radabaugh, 1976).

\section{Conclusions}

This paper identifies a new important determinant of suicide, one which has hitherto not received attention from the academic community. Movements in stock markets have a clear and recognizable effect on suicide rates across 36 countries, both contemporaneously and at a lag. The fact that the relationship is dynamic suggests a causality in the Granger (1969) sense. Although traditional finance theories articulate the financial uncertainties associated with stock investing, they overlook the risk inherent at the human level. This study widens the analytical lens in this respect and points out that financial markets have a greater resonance within society than initially envisaged by the theories. 
Our findings have a range of practical implications. First, guidance should be directed not only to the investors for whom the vagaries of the market have a direct consequence, but also to those who recommend investment plans for others. Financial advisors should bear in mind that acting in the clients' best interest requires consideration of their emotional and psychological well-being. In order to do this, assistance may be required from the medical profession. Associations of investment professionals should collaborate with mental health experts to come up with clear guidance on how to identify vulnerable individuals. Upon recognizing clients who may be at risk, advisors should recommend a low risk portfolio with an underweighting in stocks. For people with suicidal tendencies, the benefits of achieving higher expected returns from taking on additional risk pales in comparison to the threat to life that this danger presents.

The second recommendation we put forward is rooted in the fact that stock returns signal increased suicide rates ahead of time. Preventative measures, therefore, can be put in place with a reasonable expectation of success. For instance, government spending on mental health could be, to some extent, conditioned upon stock market performance. Additional resources could be made available following market crashes to help affected individuals cope with the associated financial distress. Since stock returns are forerunners to economic change, such spending would be countercyclical and would act as an automatic fiscal stabilizer. Taken together, these proposals could contribute towards creating a safer investment environment. Although it is beyond the scope of the current study, future research should endeavor to look at this phenomenon using data on an individual level. 


\section{References}

Apouey, B. and Clark, A.E. (2015). Winning big but feeling no better? The effect of lottery prizes on physical and mental health. Health Economics, 24(5), pp. 516-538.

Arellano, M. (1987). Computing robust standard errors for within-groups estimators. Oxford Bulletin of Economics and Statistics 49(4), pp. 431-434.

Baker, M. and Wurgler, J. (2007). Investor sentiment in the stock market. Journal of Economic Perspectives, 21(2), pp. 129-152.

Barr, B., Taylor-Robinson, D., Scott-Samuel, A., McKee, M. and Stuckler, D. (2012). Suicides associated with the 2008-10 economic recession in England: time trend analysis. BMJ, 345, p.e5142.

Blanchflower, D.G. and Oswald, A.J. (2004a). Money, sex and happiness: An empirical study. The Scandinavian Journal of Economics, 106(3), pp. 393-415.

Blanchflower, D.G. and Oswald, A.J. (2004b). Well-being over time in Britain and the USA. Journal of Public Economics, 88(7-8), pp. 1359-1386.

Brainerd, E. (2001). Economic reform and mortality in the former Soviet Union: a study of the suicide epidemic in the 1990s. European Economic Review, 45(4-6), pp. 1007-1019.

Burr, J.A., McCall, P.L. and Powell-Griner, E. (1994). Catholic religion and suicide: the mediating effect of divorce. Social Science Quarterly, 75(2), pp. 300-18.

Chen, J., Choi, Y.J. and Sawada, Y. (2009). How is suicide different in Japan?. Japan and the World Economy, 21(2), pp. 140-150.

Chen, J., Choi, Y.J., Mori, K., Sawada, Y. and Sugano, S. (2012). Socio-economic studies on suicide: A survey. Journal of Economic Surveys, 26(2), pp. 271-306.

Cotti, C., Dunn, R.A. and Tefft, N. (2015). The Dow is killing me: Risky health behaviors and the stock market. Health Economics, 24(7), pp. 803-821.

Currie, J. and Tekin, E. (2015). Is there a link between foreclosure and health?. American Economic Journal: Economic Policy, 7(1), pp. 63-94.

Desai, R.A., Dausey, D.J. and Rosenheck, R.A. (2005). Mental health service delivery and suicide risk: the role of individual patient and facility factors. American Journal of Psychiatry, 162(2), pp. 311-318.

Dickey, D.A. and Fuller, W.A. (1979). Distribution of the estimators for autoregressive time series with a unit root. Journal of the American Statistical Association, 74(366a), pp. 427-431.

Durkheim, E. (1897). Suicide. Translated by J. Spaulding and Simpson, G. Reprinted Glencoe: Ill: Free Press, 1951.

Easterlin, R.A. (1995). Will raising the incomes of all increase the happiness of all?. Journal of Economic Behavior \& Organization, 27(1), pp. 35-47.

Engelberg, J. and Parsons, C.A. (2016). Worrying about the stock market: Evidence from hospital admissions. Journal of Finance, 71(3), pp. 1227-1250.

Estrella, A. and Mishkin, F.S. (1998). Predicting US recessions: Financial variables as leading indicators. Review of Economics and Statistics, 80(1), pp. 45-61.

Faupel, C.E., Kowalski, G.S. and Starr, P.D. (1987). Sociology's one law: Religion and suicide in the urban context. Journal for the Scientific Study of Religion, 26(4), pp. 523-534. 
Freeman, D.G. (1998). Determinants of Youth Suicide. American Journal of Economics and Sociology, 57(2), pp. 183-200.

Frey, B.S. and Stutzer, A. (2000). Happiness, economy and institutions. The Economic Journal, 110(466), pp. 918-938.

Frey, B.S. and Stutzer, A. (2002). What can economists learn from happiness research?. Journal of Economic Literature, 40(2), pp. 402-435.

Galbraith, J.K. (1997). The great crash of 1929. Houghton Mifflin Company: Boston, MA.

Galea, S., Tracy, M., Norris, F. and Coffey, S.F. (2008). Financial and social circumstances and the incidence and course of PTSD in Mississippi during the first two years after Hurricane Katrina. Journal of Traumatic Stress, 21(4), pp. 357-368.

Ganzini, L., McFarland, B.H. and Cutler, D. (1990). Prevalence of mental disorders after catastrophic financial loss. The Journal of Nervous and Mental Disease, 178(11), pp. 680-685.

Gardner, J. and Oswald, A.J. (2007). Money and mental wellbeing: A longitudinal study of mediumsized lottery wins. Journal of Health Economics, 26(1), pp. 49-60.

Gili, M., Roca, M., Basu, S., McKee, M. and Stuckler, D. (2012). The mental health risks of economic crisis in Spain: evidence from primary care centres, 2006 and 2010. The European Journal of Public Health, 23(1), pp. 103-108.

Granger, C. W. J. (1969). Investigating Casual Relations by Econometric Models and Cross Spectral Methods. Econometrica, 37(3), pp. 424-438.

Hausman, J.A. (1978). Specification tests in econometrics. Econometrica, 46(6), pp. 1251-1271.

Helliwell, J.F. (2007). Well-being and social capital: Does suicide pose a puzzle?. Social Indicators Research, 81(3), pp. 455-496.

Henry, A.F. and Short, J.F. (1954). Suicide and homicide: Some economic, sociological and psychological aspects of aggression. Free Press: New York.

Huang, W.C. (1996). Religion, culture, economic and sociological correlates of suicide rates: a crossnational analysis. Applied Economics Letters, 3(12), pp. 779-782.

Im, K.S., Pesaran, M.H. and Shin, Y. (2003). Testing for unit roots in heterogeneous panels. Journal of Econometrics, 115(1), pp. 53-74.

Inglegart, R. and Rabier, J.R. (2000). Genes, culture, and happiness. In Diener, E. and Suh, E.M. (eds.). Subjective well-being across cultures, MIT Press: Cambridge, M.A.

Jungeilges, J. and Kirchgässner, G. (2002). Economic welfare, civil liberty, and suicide: an empirical investigation. The Journal of Socio-Economics, 31(3), pp. 215-231.

Kim, B. and Ruhm, C.J. (2012). Inheritances, health and death. Health Economics, 21(2), pp.127-144.

Kimenyi, M.S. and Shughart, W.F. (1986). Economics of suicide: Rational or irrational choice. Atlantic Economic Journal, 14(1), pp. 120-121.

Klick, J. and Markowitz, S. (2006). Are mental health insurance mandates effective? Evidence from suicides. Health Economics, 15(1), pp. 83-97.

Koo, J. and Cox, W.M. (2008). An economic interpretation of suicide cycles in Japan. Contemporary Economic Policy, 26(1), pp. 162-174.

Landberg, J. (2009). Per capita alcohol consumption and suicide rates in the US, 1950-2002. Suicide and Life-Threatening Behavior, 39(4), pp. 452-460. 
Lester, D. (1995). Explaining regional differences in suicide rates. Social Science \& Medicine, 40(5), pp. 719-721.

Leonard, K. (2001). Domestic violence and alcohol: what is known and what do we need to know to encourage environmental interventions?. Journal of Substance Use, 6(4), pp. 235-247.

Lester, B.Y. (2001). Learnings from Durkheim and beyond: the economy and suicide. Suicide and LifeThreatening Behavior, 31(1), pp. 15-31.

Levin, K.A. and Leyland, A.H. (2005). Urban/rural inequalities in suicide in Scotland, 1981-1999. Social Science \& Medicine, 60(12), pp. 2877-2890.

Lewis, G. and Sloggett, A. (1998). Suicide, deprivation, and unemployment: record linkage study. British Medical Journal, 317(7168), pp. 1283-1286.

Lin, H., Ketcham, J.D., Rosenquist, J.N. and Simon, K.I. (2013). Financial distress and use of mental health care: Evidence from antidepressant prescription claims. Economics Letters, 121(3), pp. 449-453.

Lindahl, M. (2005). Estimating the effect of income on health and mortality using lottery prizes as an exogenous source of variation in income. Journal of Human Resources, 40(1), pp. 144-168.

Lowenthal, B. (1987). The jumpers of '29. The Washington Post, Oct 25, 1987.

Luttmer, E.F., 2005. Neighbors as negatives: Relative earnings and well-being. The Quarterly Journal of Economics, 120(3), pp. 963-1002.

Maddala, G.S. and Wu, S. (1999). A comparative study of unit root tests with panel data and a new simple test. Oxford Bulletin of Economics and Statistics, 61(S1), pp. 631-652.

Mathur, V.K. and Freeman, D.G. (2002). A theoretical model of adolescent suicide and some evidence from US data. Health Economics, 11(8), pp. 695-708.

Matsubayashi, T. and Ueda, M. (2011). The effect of national suicide prevention programs on suicide rates in 21 OECD nations. Social Science \& Medicine, 73(9), pp. 1395-1400.

Mäkinen, I. (1997). Are there social correlates to suicide?. Social Science \& Medicine, 44(12), pp. 19191929.

Mclnerney, M., Mellor, J.M. and Nicholas, L.H. (2013). Recession depression: Mental health effects of the 2008 stock market crash. Journal of Health Economics, 32(6), pp. 1090-1104.

Minoiu, C. and Rodríguez Andrés, A. (2008). The effect of public spending on suicide: evidence from US state data. The Journal of Socio-Economics, 37(1), pp. 237-261.

Morselli, H. (1882). Suicide: An essay on comparative moral statistics. D. Appleton and Company: New York.

Mościcki, E.K. (1994). Gender Differences in Completed and Attempted Suicide. Annals of Epidemiology, 4(2), pp. 152-158.

Mullis, R.J. (1992). Measures of economic well-being as predictors of psychological well-being. Social Indicators Research, 26(2), pp. 119-135.

Neumayer, E. (2003). Are socioeconomic factors valid determinants of suicide? Controlling for national cultures of suicide with fixed-effects estimation. Cross-cultural research, 37(3), pp. 307-329.

Norström, T. (1988). Alcohol and suicide in Scandinavia. British Journal of Addiction, 83(5), pp. 553559.

Oyesanya, M., Lopez-Morinigo, J. and Dutta, R. (2015). Systematic review of suicide in economic recession. World Journal of Psychiatry, 5(2), pp. 243-254. 
Paul, K.I. and Moser, K. (2009). Unemployment impairs mental health: Meta-analyses. Journal of Vocational Behavior, 74(3), pp. 264-282.

Pearlin, L.I. and Radabaugh, C.W. (1976). Economic strains and the coping function of alcohol. American Journal of Sociology, 82(3), pp. 652-663.

Phillips, J.A. and Nugent, C.N. (2014). Suicide and the Great Recession of 2007-2009: the role of economic factors in the 50 US states. Social Science \& Medicine, 116, pp. 22-31.

Pierce, A. (1967). The economic cycle and the social suicide rate. American Sociological Review, 32(3), pp. 457-462.

Riedman, D. and Warden, C.J. (2017). The cold war on terrorism: Reevaluating critical infrastructure facilities as targets for terrorist attacks. Homeland Security Affairs, 16, pp. 2-24.

Rodríguez Andrés, A. (2005). Income inequality, unemployment, and suicide: a panel data analysis of 15 European countries. Applied Economics, 37(4), pp. 439-451.

Rogers, W. (1929). Will Rogers says New York has had a 'wailing day'. The New York Times, Oct 25, 1929.

Ruhm, C.J. (2000). Are recessions good for your health?. The Quarterly Journal of Economics, 115(2), pp. 617-650.

Ruhm, C.J. (2005). Healthy living in hard times. Journal of Health Economics, 24(2), pp. 341-363.

Shah, A. and Bhat, R. (2008). The relationship between elderly suicide rates and mental health funding, service provision and national policy: a cross-national study. International Psychogeriatrics, 20(3), pp. 605-615.

Simpson, M.E. and Conklin, G.H. (1989). Socioeconomic development, suicide and religion: A test of Durkheim's theory of religion and suicide. Social Forces, 67(4), pp. 945-964.

Smart, R.G. and Mann, R.E. (1990). Changes in suicide rates after reductions in alcohol consumption and problems in Ontario, 1975-1983. Addiction, 85(4), pp. 463-468.

Stack, S. (1998). The relationship of female labor force participation to suicide: a comparative analysis. Archives of Suicide Research, 4(3), pp. 249-261.

Stack, S. and Bowman, B. (2014). Men, economic strain, and suicide in the movies, 1900-2013. In Lester, D., Gunn, J. and Quinnett, P. (Eds). Suicide in Men: How Men Differ from Women in Expressing their Distress, Chapter 22, Charles Thomas: Springfield, Illinois.

Stack, S. and Wasserman, I. (1993). Marital status, alcohol consumption, and suicide: An analysis of national data. Journal of Marriage and the Family, 55(4), pp. 1018-1024.

Stark, C., Hopkins, P., Gibbs, D., Belbin, A. and Hay, A. (2007). Population density and suicide in Scotland. Rural Remote Health, 7(3), pp. 672-685.

Stevenson, B. and Wolfers, J. (2006). Bargaining in the shadow of the law: Divorce laws and family distress. Quarterly Journal of Economics, 121(1), pp. 267-288.

Stock, J.H. and Watson, M.W. (1989). New indexes of coincident and leading economic indicators. NBER Macroeconomics Annual, 4, pp. 351-394.

Stuart, H. (2006). Mental illness and employment discrimination. Current Opinion in Psychiatry, 19(5), pp. 522-526.

Yang, B. and Lester, D. (1999). The misery index and suicide. Psychological Reports, 84(3), pp. 10861086. 


\section{Appendix}

\section{List of Countries Included in Our Sample}

Australia, Austria, Belgium, Brazil, Canada, Chile, Colombia, Czech Republic, Denmark, Estonia, Finland, France, Germany, Great Britain, Greece, Hungary, Ireland, Israel, Italy, Japan, Lithuania, Mexico, Netherlands, New Zealand, Norway, Poland, Portugal, Republic of Korea, Russia, Slovenia, South Africa, Spain, Sweden, Switzerland, Turkey, United States 
Table I

Definitions of Variables and Their Data Sources

\begin{tabular}{|c|c|c|}
\hline & Variable Definition & Data Source \\
\hline Suicide_Overall & Total suicide rate per 100,000 persons & OECD Health Statistics \\
\hline Suicide_Male & Suicide rate per 100,000 men & OECD Health Statistics \\
\hline Suicide_Female & Suicide rate per 100,000 women & OECD Health Statistics \\
\hline pcSuicide_Overall & Percentage change in the Suicide_Overall variable & OECD Health Statistics \\
\hline pcSuicide_Male & Percentage change in the Suicide_Male variable & OECD Health Statistics \\
\hline pcSuicide_Female & Percentage change in the Suicide_Female variable & OECD Health Statistics \\
\hline Returns & $\begin{array}{l}\text { US dollar-denominated, continuously compounded } \\
\text { return on country-level capitalization-weighted MSCI } \\
\text { stock market index }\end{array}$ & Thomson Reuters Datastream \\
\hline GDP_Growth & Annual growth in the Gross Domestic Product & World Development Indicators \\
\hline pcUnemployment & $\begin{array}{l}\text { Percentage change in the unemployment rate (national } \\
\text { estimate) }\end{array}$ & World Development Indicators \\
\hline Inflation & Inflation in consumer prices & World Development Indicators \\
\hline pcFertility & $\begin{array}{l}\text { Percentage change in the fertility rate (defined as births } \\
\text { per female) }\end{array}$ & World Development Indicators \\
\hline pcFemPart & $\begin{array}{l}\text { Percentage change in female labor force participation } \\
\text { rate for females above the age of } 15 \text { (ILO estimate) }\end{array}$ & World Development Indicators \\
\hline pcAlcohol & $\begin{array}{l}\text { Percentage change in pure alcohol consumption per } \\
\text { person aged } 15 \text { years and over. }\end{array}$ & OECD Health Statistics \\
\hline pcDensity & $\begin{array}{l}\text { Percentage change in population density (people per sq- } \\
\mathrm{km} \text { of land area) }\end{array}$ & World Development Indicators \\
\hline pcDivorces & Percentage change in crude divorce rates & $\begin{array}{l}\text { OECD Family Database, } \\
\text { Eurostat }\end{array}$ \\
\hline pcHealth & Percentage change in health expenditure to GDP ratio & World Development Indicators \\
\hline
\end{tabular}


Table II

\section{Summary Statistics}

\begin{tabular}{lccccc}
\hline \hline & & & \multicolumn{2}{c}{ Panel Unit Root Tests } \\
\cline { 5 - 6 } & No. Obs. & Average & $\begin{array}{c}\text { Standard } \\
\text { Deviation }\end{array}$ & IPS test & MW test \\
\hline Suicide_Overall & 1,627 & 15.0701 & 9.3924 & 1.5633 & 68.5279 \\
Suicide_Male & 1,627 & 24.0269 & 15.8163 & 0.8848 & 71.3459 \\
Suicide_Female & 1,627 & 7.4970 & 4.9841 & 0.3154 & 80.3992 \\
pcSuicide_Overall & 1,574 & 0.0033 & 0.1258 & $-37.1509^{* * * *}$ & $945.1013^{* * *}$ \\
pcSuicide_Male & 1,574 & 0.0046 & 0.1302 & $-38.6336^{* * * *}$ & $985.4478^{* * *}$ \\
pcSuicide_Female & 1,574 & 0.0062 & 0.1820 & $-39.9707^{* * * *}$ & $1032.2587^{* * *}$ \\
Returns & 1,149 & 0.0630 & 0.0918 & $-28.2801^{* * * *}$ & $774.0019^{* * *}$ \\
GDP_Growth & 1,660 & 0.0337 & 0.0336 & $-19.9533^{* * * *}$ & $521.9543^{* * *}$ \\
pcUnemployment & 1,312 & 0.1141 & 1.8529 & $-102.6341^{* * * *}$ & $1360.4409^{* * * *}$ \\
Inflation & 1,701 & 0.1795 & 1.1743 & $-16.2874^{* * * *}$ & $495.5152^{* * *}$ \\
pcFertility & 1,944 & -0.0108 & 0.0335 & $-13.9637^{* * * *}$ & $371.6729^{* * * *}$ \\
pcFemPart & 864 & 0.0053 & 0.0214 & $-19.2169^{* * * *}$ & $535.5727^{* * * *}$ \\
pcAlcohol & 1,797 & 0.0053 & 0.0639 & $-32.5910^{* * * *}$ & $936.1828^{* * *}$ \\
pcDensity & 1,869 & 0.0080 & 0.0080 & $-5.3122^{* * * *}$ & $171.9607^{* * *}$ \\
pcDivorces & 1,363 & 0.0246 & 0.1208 & $-30.0115^{* * * *}$ & $821.1738^{* * *}$ \\
pcHealth & 684 & 0.0142 & 0.0493 & $-16.2029^{* * * *}$ & $326.5228^{* * *}$ \\
\hline \hline
\end{tabular}

Note: This table presents basic summary statistics for the variables used in the study. For definitions of these variables please refer to Table I. IPS test stands for the panel unit root test proposed by Im, Pesaran and Shin (2003), while the MW test is based on a methodological approach outlined in Maddala and Wu (1999). ${ }^{* * *}$ denotes rejection of the null hypothesis of unit root at the $1 \%$ significance level. 
Table III

Pearson Correlation Coefficients

\begin{tabular}{lccc}
\hline \hline & $p c$ Suicide_Overall & $p c$ Suicide_Male & pcSuicide_Female \\
\hline Returns & $-0.0802^{* * *}$ & $-0.0737^{* *}$ & -0.0440 \\
Returns_Lagged & $-0.1041^{* * *}$ & $-0.0852^{* * *}$ & $-0.0745^{* *}$ \\
GDP_Growth & $-0.0504^{* *}$ & $-0.0578^{* *}$ & -0.0166 \\
pcUnemployment & $0.0760^{* * *}$ & $0.0699^{* *}$ & 0.0305 \\
Inflation & 0.0307 & 0.0400 & 0.0078 \\
pcFertility & $-0.0869^{* * *}$ & $-0.0746^{* * *}$ & $-0.0760^{* * *}$ \\
pcFemPart & -0.0140 & -0.0401 & 0.0191 \\
pcAlcohol & 0.0350 & 0.0259 & 0.0292 \\
pcDensity & $0.0655^{* *}$ & $0.0610^{* *}$ & $0.0758^{* * *}$ \\
pcDivorces & $0.0800^{* * *}$ & $0.0879^{* * *}$ & 0.0349 \\
pcHealth & $0.0746^{*}$ & 0.0643 & 0.0449 \\
pcHealth_Lagged & -0.0162 & -0.0158 & -0.0060 \\
\hline \hline
\end{tabular}

Note: This table reports correlation coefficients between the variables with the corresponding significance level. Exact definitions of the variables are provided in Table I. Returns_Lagged and pcHealth_Lagged represent the original variables lagged by one period. ${ }^{* * *},{ }^{* *},{ }^{*}$ denote statistical significance at $1 \%, 5 \%$ and $10 \%$, respectively. 


\section{Table IV}

\section{Determinants of the Percentage Changes in the Overall Suicide Rate}

(1)

Pooled OLS $\quad$ Fixed Effects Panel Fixed Effects Panel Fixed Effects Panel

\begin{tabular}{|c|c|c|c|c|}
\hline Intercept & $\begin{array}{c}0.0035 \\
(0.0026)\end{array}$ & & & \\
\hline Returns & $\begin{array}{l}-0.0230^{* * * *} \\
(0.0078)\end{array}$ & $\begin{array}{l}-0.0158^{* * *} \\
(0.0055)\end{array}$ & $\begin{array}{l}-0.0215^{\text {*** }} \\
(0.0066)\end{array}$ & $\begin{array}{l}-0.0157^{* *} \\
(0.0064)\end{array}$ \\
\hline Returns_Lagged & $\begin{array}{l}-0.0280^{* * * *} \\
(0.0076)\end{array}$ & $\begin{array}{l}-0.0227^{* * *} \\
(0.0061)\end{array}$ & $\begin{array}{l}-0.0191^{*} \\
(0.0113)\end{array}$ & $\begin{array}{l}-0.0285^{\text {*** }} \\
(0.0065)\end{array}$ \\
\hline GDP_Growth & & & $\begin{array}{l}-0.2936^{* *} \\
(0.1307)\end{array}$ & \\
\hline pcUnemployment & & & $\begin{array}{c}0.0366^{*} \\
(0.0212)\end{array}$ & $\begin{array}{l}0.0441^{* * *} \\
(0.0143)\end{array}$ \\
\hline Inflation & & & $\begin{array}{c}0.2644^{*} \\
(0.1552)\end{array}$ & $\begin{array}{l}0.1822^{* * *} \\
(0.0179)\end{array}$ \\
\hline pcFertility & & & $\begin{array}{c}0.0536 \\
(0.1004)\end{array}$ & \\
\hline pcFemPart & & & $\begin{array}{l}-0.4619^{* *} \\
(0.1964)\end{array}$ & $\begin{array}{l}-0.5020^{* * *} \\
(0.1405)\end{array}$ \\
\hline pcAlcohol & & & $\begin{array}{l}-0.0439 \\
(0.0633)\end{array}$ & \\
\hline pcDensity & & & $\begin{array}{l}-0.0082 \\
(0.5579)\end{array}$ & \\
\hline pcDivorces & & & $\begin{array}{c}0.0006 \\
(0.0305)\end{array}$ & \\
\hline pcHealth & & & $\begin{array}{c}0.0414 \\
(0.0649)\end{array}$ & \\
\hline pcHealth_Lagged & & & $\begin{array}{l}-0.0918 \\
(0.0697)\end{array}$ & $\begin{array}{l}-0.1325^{* * *} \\
(0.0468)\end{array}$ \\
\hline No. obs. & 1067 & 1067 & 470 & 571 \\
\hline R-squared & $1.8951 \%$ & $8.1774 \%$ & 25.8740 & $25.0106 \%$ \\
\hline F-statistic & 10.2767 & 2.4767 & 3.3716 & 4.3032 \\
\hline Prob (F-stat) & 0.0000 & 0.0000 & 0.0000 & 0.0000 \\
\hline
\end{tabular}

Note: The dependent variable in the regressions reported in this table is the percentage change in the total suicide rate. Column (1) reports the estimates derived from a pooled OLS estimation approach, while columns (2)-(4) employ fixed effects panel with cross-sectional weighting and White period standard errors. For definitions of the variables please consult Table I. ${ }^{* * *},{ }^{* *},{ }^{*}$ denote statistical significance at $1 \%, 5 \%$ and $10 \%$, respectively. 
Table V

Determinants of the Percentage Changes in the Male Suicide Rate

\begin{tabular}{|c|c|c|c|c|}
\hline & $\begin{array}{c}(1) \\
\text { Pooled OLS }\end{array}$ & $\begin{array}{c}(2) \\
\text { Fixed Effects Panel }\end{array}$ & $\begin{array}{c}\text { (3) } \\
\text { Fixed Effects Panel }\end{array}$ & $\begin{array}{c}\text { (4) } \\
\text { Fixed Effects Panel }\end{array}$ \\
\hline Intercept & $\begin{array}{r}0.0053^{*} \\
(0.0030)\end{array}$ & & & \\
\hline Returns & $\begin{array}{l}-0.0245^{* * *} \\
(0.0091)\end{array}$ & $\begin{array}{l}-0.0154^{* * *} \\
(0.0057)\end{array}$ & $\begin{array}{l}-0.0209^{* * *} \\
(0.0076)\end{array}$ & $\begin{array}{l}-0.0132^{*} \\
(0.0070)\end{array}$ \\
\hline Returns_Lagged & $\begin{array}{l}-0.0270^{* * *} \\
(0.0088)\end{array}$ & $\begin{array}{l}-0.0207^{* * *} \\
(0.0065)\end{array}$ & $\begin{array}{l}-0.0246^{* *} \\
(0.0122)\end{array}$ & $\begin{array}{l}-0.0264^{* * *} \\
(0.0067)\end{array}$ \\
\hline GDP_Growth & & & $\begin{array}{l}-0.1509 \\
(0.1482)\end{array}$ & \\
\hline pcUnemployment & & & $\begin{array}{l}0.0615^{* *} \\
(0.0238)\end{array}$ & $\begin{array}{l}0.0550^{* * *} \\
(0.0163)\end{array}$ \\
\hline Inflation & & & $\begin{array}{r}0.3049^{*} \\
(0.1637)\end{array}$ & $\begin{array}{l}0.2067^{* * *} \\
(0.0184)\end{array}$ \\
\hline pcFertility & & & $\begin{array}{c}0.0939 \\
(0.1212)\end{array}$ & \\
\hline pcFemPart & & & $\begin{array}{l}-0.5571^{* * *} \\
(0.2138)\end{array}$ & $\begin{array}{l}-0.6391^{* * *} \\
(0.1454)\end{array}$ \\
\hline pcAlcohol & & & $\begin{array}{l}-0.0103 \\
(0.0714)\end{array}$ & \\
\hline pcDensity & & & $\begin{array}{l}-0.3432 \\
(0.5860)\end{array}$ & \\
\hline pcDivorces & & & $\begin{array}{c}0.0225 \\
(0.0330)\end{array}$ & \\
\hline pcHealth & & & $\begin{array}{l}-0.0040 \\
(0.0594)\end{array}$ & \\
\hline pcHealth_Lagged & & & $\begin{array}{l}-0.0912 \\
(0.0649) \\
\end{array}$ & $\begin{array}{l}-0.1408^{* * *} \\
(0.0472) \\
\end{array}$ \\
\hline No. obs. & 1067 & 1067 & 470 & 571 \\
\hline R-squared & $1.4008 \%$ & $6.9005 \%$ & 24.3537 & $17.3951 \%$ \\
\hline F-statistic & 7.5583 & 2.0613 & 3.1097 & 3.9276 \\
\hline Prob (F-stat) & 0.0006 & 0.0002 & 0.0000 & 0.0000 \\
\hline
\end{tabular}

Note: The dependent variable in the regressions reported in this table is the percentage change in the male suicide rate. Column (1) applies a pooled OLS estimation approach, while columns (2)-(4) report the findings from the fixed effects panels with cross-sectional weighting and White period standard errors. Definitions of variables can be found in Table I. ******, ${ }^{*}$ denote statistical significance at $1 \%, 5 \%$ and $10 \%$, respectively. 
Table VI

Determinants of the Percentage Changes in the Female Suicide Rate

(1)

Pooled OLS Fixed Effects Panel Fixed Effects Panel Fixed Effects Panel

\begin{tabular}{|c|c|c|c|c|}
\hline Intercept & $\begin{array}{c}0.0032 \\
(0.0039)\end{array}$ & & & \\
\hline Returns & $\begin{array}{l}-0.0205^{*} \\
(0.0118)\end{array}$ & $\begin{array}{l}-0.0137^{*} \\
(0.0071)\end{array}$ & $\begin{array}{l}-0.0248^{* *} \\
(0.0103)\end{array}$ & $\begin{array}{l}-0.0152^{* *} \\
(0.0069)\end{array}$ \\
\hline Returns_Lagged & $\begin{array}{l}-0.0299^{* * *} \\
(0.0115)\end{array}$ & $\begin{array}{l}-0.0225^{* * *} \\
(0.0066)\end{array}$ & $\begin{array}{c}0.0010 \\
(0.0128)\end{array}$ & $\begin{array}{l}-0.0215^{* * *} \\
(0.0068)\end{array}$ \\
\hline GDP_Growth & & & $\begin{array}{l}-0.6026^{* *} \\
(0.2387)\end{array}$ & \\
\hline pcUnemployment & & & $\begin{array}{l}-0.0335 \\
(0.0358)\end{array}$ & \\
\hline Inflation & & & $\begin{array}{c}0.1363 \\
(0.1638)\end{array}$ & $\begin{array}{l}0.0008^{* * *} \\
(0.0003)\end{array}$ \\
\hline pcFertility & & & $\begin{array}{l}-0.1265 \\
(0.1101)\end{array}$ & $\begin{array}{l}-0.2106^{* * *} \\
(0.0641)\end{array}$ \\
\hline pcFemPart & & & $\begin{array}{l}-0.1009 \\
(0.3424)\end{array}$ & \\
\hline pcAlcohol & & & $\begin{array}{c}0.1533 \\
(0.0971)\end{array}$ & $\begin{array}{l}0.1543^{* *} \\
(0.0612)\end{array}$ \\
\hline pcDensity & & & $\begin{array}{c}0.2017 \\
(1.0496)\end{array}$ & \\
\hline pcDivorces & & & $\begin{array}{l}-0.0193 \\
(0.0635)\end{array}$ & \\
\hline pcHealth & & & $\begin{array}{c}0.0652 \\
(0.1003)\end{array}$ & \\
\hline pcHealth_Lagged & & & $\begin{array}{c}0.0019 \\
(0.1237) \\
\end{array}$ & \\
\hline No. obs. & 1067 & 1067 & 470 & 1045 \\
\hline R-squared & $0.8363 \%$ & $5.4599 \%$ & $15.4210 \%$ & $6.7782 \%$ \\
\hline F-statistic & 4.4868 & 1.6061 & 1.7611 & 1.8250 \\
\hline Prob (F-stat) & 0.0115 & 0.0129 & 0.0027 & 0.0015 \\
\hline
\end{tabular}

Note: The dependent variable being modeled in this table is the percentage change in the female suicide rate. Pooled OLS estimation results are shown in Column (1). The remaining three columns relate to fixed effects panels with cross-sectional weighting and White period standard errors. Variable definitions are given in Table I. ${ }^{* * *},{ }^{* * *},{ }^{*}$ denote statistical significance at $1 \%, 5 \%$ and $10 \%$, respectively. 